\title{
SOBRE L'ACTIVITAT DE LA JUSTÍCIA A UN MENUT POBLE VALENCIÀ D'INICIS DEL SEGLE XV: XIXONA (1413).
}

\author{
Enric Guinot
}

Universitat de València

Entre les variades formes documentals que existeixen per a apropar-se a la història del sistema judicial en el món medieval, així com a la sociologia i antropologia del delicte, el cos fonamental són les actes del Justícia local de cada població; al cas del País Valencià, aquest actuava com a jutge de primera instància en tota la casuística de plets i baralles, civils i criminals, en què es veien immersos els seus conveïns.

Sobre la història i característiques de les funcions d'aquests Justícies dels municipis medievals valencians existeix ja una certa oferta de treballs, des dels més antics de F.Roca Traver (1970) o J.Lalinde (1967) al ja ample ventall ofertat per R.Narbona, (1986) i (1990) especialment.

Tot i això, aquesta dedicació investigadora ha estat centrada fins el present en el cas de la ciutat de València, un cas concret de gran nucli de poblament a les darreries de l'època medieval, i, a més a més, amb especial incidència en les fonts de tipus criminal: les actes del Justícia criminal han fornit bona part dels estudis sobre la violència, els conflictes socials, les bandositats i/o la repressió de la sexualitat.

Per contra, les sèries de la justícia civil, també conservades al cas de la ciutat de València i per a alguns altres arxius municipals de les principals viles de reialenc valencianes, no han gaudit d'una atenció semblant, essent reflexe aquestes fonts, però, d'un àmbit diferent de conflictivitat i problemes de convivència social.

És per això que aportem en aquest treball un tipus de font que no ha estat treballada fins ara, relacionada directament amb aquest tema. malgrat que amb un aport d'informació molt telegràfica $i$ que sols podrem emprar com aproximació a aquesta temàtica. Malgrat tot, la considerem d'interés en raó de les dificultats de trobar documentació seriada per al món medieval així com el buit de fonts que pateixen freqüentment les viles medievals. 
El text en concret transcrit a l'apèndix és un llibre de comptabilitat del Justícia de la vila de Xixona, corresponent a les multes que va imposar en l'exercici de la seua funció durant l'any 1413. Probablement en raó de la revisió de les rendes i comptes de cadascuna de les batllies locals valencianes que va emprendre el nou Batlle General del Regne, micer Berenguer Mercader, per a controlar els ingressos del patrimoni reial arran de la proclamació del nou monarca Ferran d'Antequera, el batlle local de Xixona, juntament amb la informació sobre rendes de la vila va remetre també un quadern del Justícia de Xixona amb la liquidació financera de les multes que havia imposat durant l'any del seu ofici.

Gràcies a això, disposem d'un inventari amb el sistema d'entrades per ítems on en dues o tres línies, el Justícia enumerava el tipus de delicte que havia jutjat, el nom del veí objecte de la multa corresponent, la data del fet i el valor de la multa imposada --ban--. Com pot constatar-se, no es tracta de la prolixa informació que pot trobar-se en les actes judicials corresponents, però freturant d'aquestes venen a ser una curiosa aproximació sociològica a una menuda comunitat rural del sud del País Valencià a inicis del segle XV.

Xixona era una vila de reialenc situada a l'antiga frontera del regne de Jaume I del segle XIII, i que va restar a partir de 1298 al rerapaís muntanyenc i ramader. No apareix en els llistats del morabatí més antics, font fiscal emprada demogràficament en els estudis sobre aquests segles, però en els inventaris de la Generalitat valenciana de 1404 a 1409 per a repartir la tatxa del compartiment aprovat en Corts entre el braç reial, apareix amb 105 focs, la qual cosa la situa com la vila de reialenc més menuda d'aqueix temps i fa que la identifiquem com un molt xicotet poble rural, amb una diversificació social mínima car quasi tots els seus veïns haurien de ser llauradors i ramaders. Al llarg del segle XV sembla que degué anar creixent lentament, la qual cosa no seria la tendència general demogràfica de bona part del País Valencià interior en aquesta època; segons R.Garcia Carcel (1976), Xixona tenia 181 focs en 1451 i 1463, 204 en 1469 i 220 en 1481, apareixent amb 291 focs i 6.770 caps de bestiar en l'inventari de la tatxa de 1510 . Més enllà dels problemes de la validesa d'aquestes xifres fiscals, les quals a més tenen orígens diferents, faria pensar en una certa infravaloració de les dades de 1405-1409, tot i que no ultrapassaria l'esmentat nivell d'un menut poble rural entre 100 i 130 focs.

Pensem que és en aquest panorama demogràfic i social tan diferent del d'una ciutat medieval amb uns grups i classes socials molt més diversificats, on cal situar i entendre la font que ara aportem; i també, però, per allò que reflexa de les pautes generals de la vida quotidiana i la concreció que prenien els conflictes de convivència al si d'aquest menut cos social rural.

Una consideració que cal fer primerament és el de la crítica heurística de la font; aquesta presenta unes limitacions no sols en la forma sinó també en el seu contingut. Això és, seria erroni considerar que 
mitjançant aquests tipus de quaderns de comptabilitat de les multes dels Justícies podem fer un estudi total d'aqueixa conflictivitat social i de les seues raons; hem d'adonar-nos que ací sols apareixen les multes en diners imposades arran d'una denúncia o plet i sentenciades pel Justícia -potser fins $i$ tot sense procediment escrit-- però que ni tots els processos acaben en sentència condemnatòria ni aquesta és sempre i/o únicament una multa que es reflexe en un quadern d'ingressos com aquest. També és cert, per contra, la clara tendència assenyalada per R.Narbona (1986 i 1990) a monetitzar al màxim les penes dels delictes en raó d'aconseguir una millora de la recaptació de la hisenda reial ja que, de les multes que eren imposades pels Justícies, una quarta part n'eren entregades al batlle local i, en darrera instància, liquidades en la hisenda reial.

Totes aquestes consideracions són necessàries per a valorar el caràcter incomplet d'aquesta font per a l'estudi de la justícia i la conflictivitat al si de les comunitats rurals, de forma que demandes acabades en acord entre les parts, nomenament de tudors i curadors d'herències i orfes, i tota mena d'assumptes civils legals no deixarien la seua petjada en aquests quaderns de comptes, i tampoc probablement aquells delictes criminals que acabaren amb una pena corporal, no necessàriament de mort ja que la més freqüent eren els assots.

Fetes aquestes matisacions, podem adonar-nos que la conflictivitat entre els veïns al terme de Xixona en aquesta època té un component absolutament aclaparador; es tracta del conflicte quotidià entre ramaders i llauradors atès que hi ha terres cultivades que patissen les malifetes del ramat solt, $i$, en segon pla, el no respectar algun ramat les partides acotades en bovalars i deveses per a pasturatges restringits.

Sobre un total de 112 multes imposades en aqueix any pel Justícia de Xixona, un $83 \%$ corresponen a les malifetes i destrosses del ramat de pasturatge en totes les seues varietats; la resta dels "crims" dels xixonencs tenen un caràcter més personal però també lligat a la més estricta quotidianeïtat: un $11 \%$ de les multes ho són als pares de joves --i algun adult-- trobats de nit per la guàrdia anant per la vila sense llum després del toc de campana de capvespre, --el toc de seny--; més enllà de l'anècdota i la misèria de les dades, podem constatar dos components sociològics: són gent jove --homes sempre--, i van en grup en dates de l'estiu; sens dubte no és això cap sorpresa conceptual, però és de les poques vegades que trobem pistes del comportament social quotidià en els menuts pobles rurals.

La resta de les multes corresponen a tres casos de gent denunciada per furtar collites en terra d'altre --dos xiquetes i el ferrer, trobats menjant-se el raïm del veí a finals de juliol--; tres casos també de gent multada lleument sembla que per no pagar uns prèstecs entre veïns -"..de un quart que fon acussat...., lo qual era obligat en quantitat de 10 sous a'n..."---, i darrerament, un cas d'un veí denunciat per una dona i multat per no comparèixer a la demanda davant el Justícia, única notícia 
que ens evidencia l'existència dels plets civils que no implicaven multes i que hem considerat abans.

D'altra banda, el valor econòmic de les multes d'aquesta justícia ordinària local és mínim; tant per a les persones culpades, amb quantitats normalment entre 1 i 6 diners --recordem que el jornal diari agrícola en aquest temps era de 2 sous (24 diners)--, com per la recaptació total del Justícia: la renda obtinguda pel municipi per aquesta via va ser de 24 sous 7 diners, dels quals una quarta part era pagada com renda feudal al rei via batlle local, això si en sobrava després de pagades les despeses de la gestió del càrrec; ni la renda municipal ni la renda dels feudals es basava en l'aplicació de la justícia ordinària, això és meridià.

Aixi doncs, la imatge que se'ns ofereix de les tensions i baralles en aquesta vila es troba molt lluny de la violència que aflora en els carrers de la ciutat de València en aquesta mateixa època, amb els continuus enfrontaments entre bàndols --on participa gent de totes les classes socials--, i amb una marginalitat social que és reprimida més o menys clarament pel poder burgés municipal però que, en tot cas, genera testimonis escrits de la seua presència. En canvi, a la Xixona d'inicis del segle $X V$, el món rural sembla prou més pacífic sense que d'això puga deduir-se que no hi ha contradiccions i conflictes al si de la societat que no puguen aflorar en altres circumstàncies; ara per ara, però, els problemes -i sens dubte més d'un mal de cap generador d'odis veïnals-- flueixen pels camins dels bous que es mengen el blat de l'altre i els xicuelos que ixen de casa en les nits d'estiu.

No permet la documentació aprofundir més en aquest vessant sociològic de les tensions en una menuda comunitat rural valenciana del quatre-cents, però en canvi ha estat tota una sorpresa la riquesa de la font per al coneixement d'altres camps d'estudi sobre el món rural. D'una banda, el pas del veïnat per les multes del Justícia ens aporta una llarga nòmina dels residents a Xixona que ens seria desconeguda per la carència d'altres fonts: 74 noms de persona --que poden veure's a l'apèndix--, amb una proporció que, si més no, deu arribar a la meitat dels focs atribuïts al poble a hores d'ara, esdevenint una inestimable $i$ inesperada font demogràfica i onomàstica.

En segon terme, per a una època $i$ societat de la que manquem quasi totalment de llibres padrons $i$ actes municipals que fornissen la imatge del paisatge rural i la seua ordenació humana, aquesta comptabilitat judicial ens aporta una representació aproximada del que era l'espai agrari i ramader del terme de Xixona en el segle XV. A grans trets, i tal com pot veure's al mapa adjunt, el terme de Xixona té un tamany considerable però sols una part central d'ell, a les rodalies de la vila $i$ aprofitant-ne les zones més planes vora els corrents d'aigua; es tracta del riu de Serrat o de la Serra com es diu ara, i els dos barrancs que li arriben baixant de la serra de la Carrasqueta, tot abans de l'indret on hi apareix bastida la vila, conformen l'àrea conreada; sense una identificació exacta i 
diferenciada totalment per part de la documentació, podem enumerar l'existència d'una zona regada, amb el nom d'horta o hortes, i que correspon a les partides de Nuges (Nuxes), Sot i Aletgua, en les quals també hi ha referències a camps de blat; les vinyes no són molt abundants a partir d'aquesta font, i són situades a les partides de Lobera, Catelles i també a l'horta de Sot, així com són citats ocasionalment alguns altres conreus com ara lli (a l'horta de Sot), ametllers (a Pineta), figueres (a la Costa) i garroferes. La resta són els camps de cereals --sols identificats blat en general i "avena"--, estesos per les partides a peu de les serres, com ara Canal, Juncaret, Costa, Carrasques, Serrella, Pineta, Penyes Rotges, riu de Serrat i Xendiquer, sense que puguem fer una evaluació sobre la superfície cultivada.

En darrera instància, aquest tipus de documentació permet també una aproximació a l'espai ramader, quant que identifica els bovalars del terme: el de Bugaya en primer lloc, i també reben aqueix nom els de Pineta, el barranc de la Canaleta i d'Almarg o Almorayag, els quals podem veure en el mapa com tenen una ubicació forània a les zones de cultiu, malgrat que dins d'ells puguen existir alguns camps de blat, tal com és corrent a altres pobles medievals.

El llistat del ramat tampoc aporta grans novetats: el terme més comú emprat és el de bestiar en general, del qual podem sospitar que faça referència a ramat oví en bona mesura perquè aquest apareix moltes menys vegades identificat com a tal --ovelles i moltons--, mentre les cabres quasi no són citades, la qual cosa no vol dir que no foren prou més importants; els animals més citats individualment són els bous, la qual cosa ens duu a pensar que són l'animal de llaurada fonamental --sols hi ha citats dos rocins--, i la resta del ramat està format per tota mena d'animals "d'albarda": muls i mules, ases i someres, els quals tenen un paper de transport $\mathrm{i}$ de treball agrari que encara resta per investigar en el camp valencià medieval.

No dóna més de si aquesta font, i sens dubte no permet una anàlisi detallada de cap dels temes sociològics, agraris, fins i tot econòmics que han estat apuntats. Resta per tant fins ací l'aportació d'aquesta documentació, que, tot i això, ens il.lustra prou fefaentment les possibilitats puntuals però insospitades dels documents medievals.

\section{BIBLIOGRAFIA}

GARCIA CÁRCEL, R. (1976): "El censo de 1510 y la población valenciana de la primera mitad del siglo XVI", Saitabi, t.XXVI, pp.171-188.

LALINDE ABADÍA, J. (1967): "El "Curia" o "cort". (Una magistratura medieval mediterránea)", Anuario de Estudios Medievales, t.4, pp.

NARBONA VIZCAÍNO, R. (1986): "El Justicia Criminal. Una corte medieval valenciana, un procedimiento judicial", Estudis Castellonencs, n.3, pp.289310. 
NARBONA VIZCAÍNO, R. (1990): Malhechores, violencia y justicia ciudadana en la Valencia bajomedieval, Ajuntament de València, Premi Senyera de 1987.

ROCA TRAVER, F. (1970): El Justicia de Valencia, 1238-1321, Ajuntament de València. 


\section{APENDIX DOCUMENTAL}

1413. Xixona.

Llibre dels comptes del Justícia de Xixona de l'any 1413, amb els ingressos procedents de les multes imposades per ell.

Arxiu del Regne de València (A.R.V.), Batlia, apèndix, $n^{\circ} 61$, fol.284ro$294 \mathrm{r}^{\circ}$.

\section{TEXT.}

[fol.284rº] Libre dels comptes que ha a donar l'onrat en Ramon Quasteló, Justícia qui fou en l'ayn de la Nativitat de nostre Senyor d'en Jesuchrist M CCCC XIII, de totes les qualònies, drets e sdeveniments e quarts segons que per avant se mostra per menut.

[Hi ha pintat un menut escut amb la part de baix ovalada, i farcit el seu interior de ratlles verticals].

[fol.284vำ] Primo, rebé lo dit Justícia ha XI de giner de ban que fon acussat n'Anthoni d'Arques perquè entrà en lo en la terra del albaral, 1 diner.

Item, rebé lo dit Justícia d'en Guilem Sengaren e d'en Bernat d'Arques e d'en Jaume Beneyto, de les sues oveles que entraren en lo bovalar, ha XI de giner, 4 diners.

Item, rebé lo dit honrat Justícia d'en Pere Bernabeu, per tal com les sues oveles eren entrades en lo bovalar, ha XI de giner, 3 diners.

Item, rebé lo dit honrat Justícia d'en Bernat Bernabeu, menor, perquè les sues oveles entraren en la quoltura del Almorayag, ha XI de giner, 3 diners.

Item, rebé lo dit honrat Justícia del quarnicer perquè lo seu bestiar entrà en la quoltura de Berenguer Colomina, ha XIX dies del mes de març, 4 diners.

Suma plàgina, 1 sou 4 diners.

[f.285ro] Item, rebé lo dit honrat Justícia d'en Francesch d'Aracil perquè los seus bous entraren dichmenge, ha denou dies del mes de març, en lo blat d'en Domingo Quarbonel, del junquaret, 1 diner.

Item, rebé lo dit honrat Justícia d'en Sanxo Verdú perquè lo seu bou entrà dichmenge ha XIX dies del mes de març en lo blat d'en Domingo Quarbonel, del junquaret, 1 diner.

Item, rebé lo dit honrat Justícia d'en Miquel d'Arques perquè los seus asens entraren en la vinya de lobera de n'Arnau Serra, dimeqres, a XXII dies del mes de març, 1 diner.

Item, rebé lo dit honrat Justícia d'en Pasqual Morant perquè lo seu asse entrà en la vinya de lobera del quapelà, dimeqres, ha XXII dies del mes de març, 1 diner. 
Item, rebé lo dit honrat Justícia d'en Francesch d'Aracil perquè los seus bous entraren en la sort d'en Arnau Serra, de Nuxes, dimeqres, ha XXII dies del mes de març, 1 diner.

Item, rebé lo dit honrat Justícia d'en Anthoni d'Arques perquè los seus bous entraren en la sort del quapelà, de Nuxes, dimeqres, ha XXII dies del mes de març, 1 diner.

Suma plàgina, 6 diners.

[f.285v] Item, rebé lo dit honrat Justícia d'en Domingo Garrigós perquè lo seu bestiar entrà en lo bovalar de Bugaya, digous, ha XXIII dies del mes de març, 10 diners.

Item, rebé lo dit honrat Justícia d'en Jaume Cremades perqè les sues cabres entraren en lo bovalar de Bugaya, dijous, ha XXIII dies del mes de març, 3 diners.

Item, rebé lo dit honrat Justícia d'en Domingo Lopiç perquè los seus asens e mul entraren en lo blat d'en Domingo Quarbonel, del pla de Bugaya, disabte ha XXV dies del mes de març, 1 diner.

Item, rebé lo dit honrat Justícia d'en Bernat Bernabeu, menor, que lo seu mul entrà en lo blat d'en Domingo Quarbonel, ha XXV dies del mes de març, 1 diner.

Item, rebé lo dit honrat Justícia d'en Bernat Bernabeu, menor, perquè lo seu mul entrà en lo blat d'en Domingo Quarbonel, disabte, ha XXV dies del mes de març, 1 diner.

Item, rebé lo dit honrat Justícia del quarnicer perquè los seus moltons entraren dimarts ha XXV dies del mes d'abril en la quoltura d'en Berenguer Colomina, 3 diners.

Suma plàgina, 1 sou 7 diners.

[f.286ro] Item, rebé lo dit honrat Justícia d'en Bernat Bernabeu, menor, perquè lo seu bestiar entrà, digous, ha XXIII dies del mes de març, en lo bovalar de Bugaya, 7 diners.

Item, rebé lo dit honrat Justícia d'en Bernat Bernabeu, menor, perquè los seus bous entraren en lo guaret e plantat d'en Francesch Quarbonel, del junquaret, divendres, ha set dies del mes d'abril, 1 diner.

Item, rebé lo dit honrat Justícia del quarnicer perquè los seus moltons eren entrats en lo guaret d'en Bernat d'Arques, de la quosta, dimeqres, ha XIII dies del mes d'abril, 3 diners.

Item, rebé lo dit honrat Justícia d'en Domingo Garigós perquè lo seu bestiar era entrat en l'avena d'en Pere Brotons de Montagut, digous, ha XIII dies del mes d'abril, 3 diners.

Item, rebé lo dit honrat Justícia d'en Anthoni d'Arques perquè los seus bous eren entrats en l'avena d'en Guilem Venrel, de Fabra, disabte, ha XV dies del mes d'abril, 1 diner.

Suma plàgina, 1 sou 2 diners.

[f.286 $\mathrm{v}^{\circ}$ ] Item, rebé lo dit honrat Justícia d'en Purag d'Alcoy perquè lo seu bestiar entrà en lo guaret d'en Ramon Quasteló, diluns, ha deset d'abril, 5 diners. 
Item, rebé lo dit honrat Justícia d'en Purag d'Alcoy perquè la sua ...fateba... entrà en lo blat d'en Sanxo Vilar, diluns, ha XVII dies del mes d'abril, 1 diner.

Item, rebé lo dit honrat Justícia d'en Guilem Garcia perquè los seus bous entraren en lo blat d'en Johan Morant, de les quarasques, dimarts ha XXV dies del mes d'abril, 1 diner.

Item, rebé lo dit honrat Justícia d'en Bernat Bernabeu, de l'almàçera, perquè los seus bous eren entrats en lo blat d'en Johan Morant, de les quarasques, sense guarda, dimarts ha XXV dies del mes d'abril, 1 diner.

Item, rebé lo dit honrat Justícia d'en Pere Despí perquè lo seu bestiar era entrat en lo guaret d'en n'Anthoni Morant, de les quarasques, disabte ha VI dies del mes de mag, 3 diners.

Suma plàgina, 11 diners.

[f.287rº] Item, rebé lo dit honrat Justícia d'en Francesch d'Aracil perquè lo seu bou era entrat en I'orta e plantat d'en Matheu Garcia, de sot, disabte, ha Vi dies del mes de mag, 1 diner.

Item, rebé lo dit honrat Justícia d'en Bernat Bernabeu, menor, perquè lo seu bou entrà en l'orta e plantat d'en Matheu Garcia, de sot, per disabte ha VI dies del mes de mag, 1 diner.

Item, rebé lo dit honrat Justícia del quarnicer perquè los seus moltons eren entrats en l'orta de sot, en lo d'en Bernat Bernabeu, menor, dimarts, ha IX dies del mes de mag, 3 diners.

Item, rebé lo dit honrat Justícia d'en Domingo Garigós perquè lo seu bestiar era entrat en lo blat d'en Pere Verdú, de la quanal, dimeqres ha $X$ dies del mes de mag, 3 diners.

Item, rebé lo dit honrat Justícia d'en Nadal Pereç perquè los seus bous eren entrats en la quoltura d'en Bernat Toregrosa, de la quanal, dichmenge ha XIIII dies del mes de mag, 1 diner.

Suma plàgina, 9 diners.

[f.287 $\mathrm{v}^{\circ}$ ] Item, rebé lo dit honrat Justícia d'en Nadal Pereç perquè los seus bous entraren en la quoltura d'en Domingo Açnar, de la quanal, dichmenge, ha XIIII dies del mes de mag, 1 diner.

Item, rebé lo dit honrat Justícia d'en Domingo Garigós perquè lo seu bestiar entrà en lo bovalar de Pineta, diluns, ha XXIX dies del mes de mag, 6 diners.

Item, rebé lo dit honrat Justícia d'en Nadal Pereç perquè los seus bous entraren en Ili d'en Matheu Garcia, de sot, dimeqres ha XXXI dies del mes de mayg, 1 diner.

Item, rebé lo dit honrat Justícia d'en Nadal Pereç perquè los seus bous eren entrats en l'orta de sot, en la terra d'en Matheu Garcia, a digous lo primer dia de juin, 1 diner.

Item, rebé lo dit honrat Justícia d'en Johan Guilem perquè atrobà son fil de nit anant per vila sense lum après lo seyn sonat, 5 diners.

Item, rebé lo dit honrat Justícia d'en Bernat Brotons perquè atrobà son fil de nit anant per vila sense lum après de seyn sonat, 3 diners. 
Suma plàgina 1 sou 5 diners.

[f.288rำ] Item, rebé lo dit honrat Justícia d'en Garcia Pereç perquè atrobà son fil anant de nit per vila après lo seyn sonat sense lum, 3 diners.

Item, rebé lo dit honrat Justícia d'en Bernat Bernabeu lo batle, que atrobà son fil anant de nit per vila sense lum après lo seyn sonat, 3 diners.

Item, rebé lo dit honrat Justícia d'Antoni d'Arques perquè les sues bèsties d'albarda e los seus bous eren entrats entre les garbes d'en Francesch d'Aracil, d'Aletgua, per digous ha XIIII dies del mes de juin, 2 diners.

Item, rebé lo dit honrat Justícia d'en Bertomeu Bernabeu perquè lo seu rocí entrà en lo blat d'en Johan Quarbonel, de Pineta, dichmenge, ha diuit dies del mes de juin, 1 diner.

Item, rebé lo dit honrat Justícia d'en Bertomeu Bernabeu perquè lo seu rocí era entrat en lo blat d'en Johan Quarbonel, de Pineta, per digous ha XXII dies del mes de juin, 1 diner.

Item, rebé lo dit honrat Justícia d'en Bertomeu Bernabeu e d'en Ivanyes Garcia perquè los seus bous eren entrats e avien talat tres figueres d'en Johan Morant, en l'orta de sot, digous ha XXII dies del mes de juin, 2 diners.

Suma plàgina, 1 sou.

[f.288vำ] Item, rebé lo dit honrat Justícia d'en Guerau Bernabeu perquè los seus moltons heren entrats en l'orta d'Aletgua, digous, ha XXII dies del mes de juin, 3 diners.

Item, rebé lo dit honrat Justícia del quarnicer perquè los seus moltons heren entrats en la terra d'en Johan de Mira, del rafal e sen qualsos, dichmenge ha II dies del mes de juliol, 3 diners.

Item, rebé lo dit honrat Justícia d'en Francesch d'Aracil perquè atrobà de nit anant per vila sense lum après lo seyn sonat, dichmenge, ha $X$ dies del mes de juliol, 2 diners.

Item, rebé lo dit honrat Justícia d'en Matheu Marquo lo qual atrobà anant de nit per vila sense lum après lo seyn sonat, dichmenge ha $X$ dies del mes de juliol, 5 diners.

Item, rebé lo dit honrat Justícia d'en Matheu Garcia, fil d'en Jaume Garcia, que atrobà après lo seyn sonat que anava de nit per vila sense lum, 4 diners.

Item, rebé lo dit honrat Justícia d'en Nadal Pere perquè los seus bous eren entrats en l'avena d'en Torregrosa, de la quanal, a dichmenge, $\mathrm{X}$ dies del mes de juliol, 2 diners.

Suma plàgina, 1 sou, 7 diners.

[f.289ro] Item, rebé lo dit honrat Justícia d'en Pere Bernabeu perquè los seus bous eren entrats en l'avena d'en Torregrosa, de la quanal, dichmenge, ha $X$ dies del mes de juliol, 1 diner.

Item, rebé lo dit honrat Justícia d'en Nadal Pereç e d'en Pere Bernabeu perquè los seus bous eren entrats entre les garbes d'en Torregrosa, de la quanal, dichmenge, ha $\mathrm{X}$ dies del mes de juliol, 2 diners. 
Item, rebé lo dit honrat Justícia d'en Nadal Pereç perquè entraren $X$ bèsties d'albarda entre les garbes d'en Torregrosa, de la quanal, per dichmenge, ha $X$ dies del mes de juliol, 1 diner.

Item, rebé lo dit honrat Justícia d'en Bernat Bernabeu e d'en Bernat Brotons perquè entraren les sues oveles en lo blat d'en Sanxo Verdú, de les Penyes Roges, disabte, ha XV dies del mes de juliol, 5 diners.

Item, rebé lo dit honrat Justícia d'en Bernat Bernabeu, menor, e d'en Bernat Brotons perquè lo seu bestiar entrà en lo plantat de Miquel Garcia, de Xendiquer, 4 diners.

Item, rebé lo dit honrat Justícia d'en Bertomeu Bernabeu perquè lo seu bestiar entrà en la orta d'Aletgua, en la terra d'en Johar. Morant, per disabte a 15 dies del mes de juliol, 1 diner.

Suma plàgina, 1 sou, 2 diners.

[f.289vo] Item, rebé lo dit honrat Justícia d'en Johan Guilem, menor de dies, que atrobà anant de nit per vila sense lum après lo seyn sonat, dichmenge a XXII dies del mes de juliol, 1 sou.

Item, rebé lo dit honrat Justícia d'en Johan Guilem perquè atrobà son fil anant per vila après lo seyn sonat sense lum, dichmenge a XXII dies del mes de juliol, 3 diners.

Item, rebé lo dit honrat Justícia del quarnicer perquè lo seu bestiar era entrat en l'orta de Sot per dichmenge ha XIII dies del mes de març, 5 diners.

Item, rebé lo dit honrat Justícia d'en Jaume Soler perquè les seus mules eren entrats en lo blat d'en Garcia Pereç, de Sot, dimarts a XIII dies del mes de març, 1 diner.

Item, rebé lo dit honrat Justícia d'en Pere Bernabeu, menor, perquè lo seu bestiar era entrat en lo bovalar del baranch de la quanaleta, 6 diners.

Item, rebé lo dit honrat Justícia d'en Bernat Bernabeu, lo batle, e d'en Bernat Brotons perquè lo seu bestiar era entrat en lo bovalar de Bugaya, diluns, ha VI dies del mes de febrer, 4 diners.

Suma plàgina, 2 sous 8 diners.

[f.290rํ] Item, rebé lo dit honrat Justícia d'en Bernat Bernabeu, menor, perquè lo seu bestiar entrà en la quoltura de Johan Colomina, de la quosta, diluns ha VI dies del mes de febrer, 5 diners.

Item, rebé lo dit honrat Justícia d'en Bernat Bernabeu, menor, perquè lo seu bestiar hera entrat en lo bovalar de Bugaya, per diluns ha VI dies del mes de febrer, 4 diners.

Item, rebé lo dit honrat Justícia del quarnicer perquè lo seu bestiar hera entrat en l'orta de Sot, en la foya d'en Bernat Bernabeu, per digous ha XV dies del mes de febrer, 3 diners.

Item, rebé lo dit honrat Justícia d'en Domingo de Blanes perquè lo seu bestiar hera entrat en lo bovalar de Bugaya, per divendres ha XVI dies del mes de febrer, 3 diners. 
Item, rebé lo dit honrat Justícia d'en Domingo Garigós perquè lo seu bestiar entrà en lo bovalar de Bugaya, diluns ha XX dies del mes de febrer, 6 diners.

Item, rebé lo dit honrat Justícia d'en Guilem Garcia per ço que lo discret en Guilem Venrel, procurador de la dona Gostança d'Almenara, l'avia ficat a quart e no comparech, dimeqres lo primer dia de març, 1 diner.

Suma plàgina, 9 diners.

[f.290vำ] Item, rebé lo dit honrat Justícia d'en Bernat d'Arques, que lo seu bestiar era entrat en lo bovalar del Almarg, dimeqres a IX dies del mes de març, 1 diner.

Item, rebé lo dit honrat Justícia d'en Francesch d'Aracil perquè la sua somera era entrada en lo blat d'Antoni d'Arques, d'Aletgua, divendres a XIIII dies del mes de juin, 1 diner.

Item, rebé lo dit honrat Justícia d'en Francesch d'Aracil perquè sa fila mengava ametles en los ametlés d'Anthoni d'Arques, de Pineta, divendres ha XIIII dies del mes de juin, 3 diners.

Item, rebé lo dit honrat Justícia del quarnicer perquè lo seu bestiar era entrat en lo plantat d'Anthoni d'Arques, d'Aletgua, dichmenge ha XVI dies del mes de juliol, 3 diners.

Item, rebé lo dit honrat Justícia del quarnicer perquè IIII quabrons eren entrats en lo plantat d'Anthoni d'Arques, d'Aletgua, per dichmenge ha XVI dies del mes de juliol, 1 diner.

Item, aquest dia matex lo dit honrat Justícia rebé del quarnicer perquè IIII quabrons eren entrats en lo plantat de Johan de Mira, d'Aletgua, per dichmenge ha XVI dies del mes de juliol, 1 diner.

Suma plàgina, 10 diners.

[f.291ro] Item, rebé lo dit honrat Justícia d'en Domingo Guaytes, d'Alquoy, perquè lo seu bestiar era entrat en lo rostol de Sanxo Sentpere, de la quanal, dichmenge a XXX dies del mes de juliol, 6 diners.

Item, rebé lo dit honrat Justícia d'en Guerau Bernabeu perquè sa filla menjava raïms en la vinya d'en Nadal Pereç, de Catelles, demarts ha XXIIII dies del mes de juliol, 5 diners.

Item, rebé lo dit honrat Justícia de la dona den Matheu Marquo perquè sa fila mengava raïms en la vinya d'en Nadal Pereç, de Quateles, per demarts ha XXIIII dies del mes de juliol, 3 diners.

Item, rebé lo dit honrat Justícia del quarnicer perquè meté lo seu bestiar en lo rostol d'en Domingo Quarbonel, de Bugaya, per diluns ha XXXI dies del mes de joliol, 2 diners.

Item, rebé lo dit honrat Justícia del quarnicer perquè meté lo seu bestiar en lo rostol d'en Domingo Quarbonel, de Bugaya, per diluns ha XXXI dies del mes de joliol, 3 diners.

Item, rebé lo dit honrat Justícia d'en Pere Espinós, d'Alquoy, perquè més lo seu bestiar en lo rostol d'en Bernat Brotons, de la quanal, per disabte ha XXX dies del mes de juliol, 4 diners.

Suma plàgina, 11 diners. 
[f.291vo] Item, rebé lo dit honrat Justícia d'en Bertomeu Bernabeu perquè més lo seu bestiar en lo blat de Guilem Enegues, de la Penya Roga, per diluns ha VIIII dies del mes d'agost, 2 diners.

Item, rebé lo dit honrat Justícia d'en Bertomeu Bernabeu perquè més lo seu bestiar en l'orta de Nuxes, XV quaps, per dimarts ha $X$ dies del mes d'agost, 1 diner.

Item, rebé lo dit honrat Justícia d'en Jaume Blasquo, ferer, perquè mengava raïmes en la vinya d'en Bertomeu Marquo, per digous ha III dies del mes d'agost, 2 diners.

Item, rebé lo dit honrat Justícia d'en Arnau Deçpí perquè més lo seu bestiar en lo plantat d'en Bernat Brotons, del riu de Serat, diluns ha VIII dies del mes de agost, 3 diners.

Item, rebé lo dit honrat Justícia d'en Arnau Deçpí perquè més lo seu bestiar en la terra d'en Ginés Fortunyo, del riu de Serat, diluns ha VIII dies del mes d'agost, 2 diners.

Item, rebé lo dit honrat Justícia d'en Bertomeu Bernabeu perquè més XV quaps de bestiar en l'orta de Nuxes, dimeqres ha $\mathrm{X}$ d'agost, 1 diner.

Suma plàgina, 11 diners.

[f.292ro] Item, rebé lo dit honrat Justícia d'en Anthoni d'Arques perquè més III bèsties d'albarda en Sot, entre les vinyes d'en Nadal Pereç, dimeqres ha $\mathrm{X}$ d'agost, 2 diners.

Item, rebé lo dit honrat Justícia d'en Anthoni d'Arques per hun bou seu lo qual pasturava en la vinya d'en Nadal Pereç, de Sot, dimeqres ha $X$ dies d'agost, 1 diner.

Item, rebé lo dit honrat Justícia d'en Bertomeu Bernabeu perquè més lo seu bestiar en lo blat d'en Sanxo Verdú, de la Penya Roga, dimegres ha XVIIII dies del mes de juliol, 2 diners.

Item, rebé lo dit honrat Justícia d'en Guerau Bernabeu perquè més lo seu bestiar en l'orta de Sot, dimarts ha XV dies del mes d'agost, 2 diners.

Item, rebé lo dit honrat Justícia d'en Bertomeu Bernabeu que més lo seu bestiar en lo blat d'en Sanxo Verdú, de les Penyes Roges, dimeqres ha XVIIII dies del mes d'agost, 2 diners.

Item, rebé lo dit honrat Justícia del quarnicer perquè més lo seu bestiar en l'orta de Sot, dimarts ha XIIII dies del mes d'agost, 2 diners.

Suma plàgina, 1 sou.

[f.292 $v^{\circ}$ ] Item, rebé lo dit honrat Justícia d'en Johan Guilem perquè anava de nit per vila aprés lo seyn sonat sense lum, dimarts ha III dies del mes d'agost, 1 sou 3 diners.

Item, rebé lo dit honrat Justícia d'en Nadal Pereç perquè atrobà son fil anant de nit per vila après la quanpana del seyn sonat sense lum, diluns ha XIIII dies del mes d'agost, 3 diners.

Item, rebé lo dit honrat Justícia d'en Nadal Pereç perquè atrobà son fil de nit anant per vila après de la quanpana del seyn sonat sense lum, dimarts ha XV dies del mes d'agost, 4 diners. 
Item, rebé lo dit honrat Justícia del quarnicer perquè avia més lo seu bestiar en lo figueral d'en Johan Guilem, de la quosta, dimarts a XXX dies del mes d'agost, 4 diners.

Item, rebé lo Justícia d'en Antoni d'Arques perquè lo seu bou hera entrat en la vinya d'en Bernat d'Almenara, dimarts a XXX d'agost, 1 diner.

Item, rebé lo dit honrat Justícia d'en Mateu Perpenyà per ço com los seus asens eren entrats en la vinya d'en Johan de Mira, del Almarg, digous ha XIIII dies del mes de setembre, 1 diner.

Item, rebé lo dit honrat Justícia d'en Johan Bernabeu per ço com los seus muls mengaven garofes en los garofés de na Serventa, digous ha XIIII dies del mes de setembre, 1 diner.

Suma plàgina, 2 sous 5 diners.

[f.293ro] Item, rebé lo dit honrat Justícia d'en Bernat Bernabeu per ço com lo seu bestiar hera entrat en lo guaret de la Penya Roga, de Guillem Enegueç, dimarts ha XVII dies del mes d'octubre, 3 diners.

Item, rebé lo dit honrat Justícia d'en Bernat Bernabeu per ço com lo seu bestiar hera entrat en lo seu guaret de Sereya, dimarts ha XXIIII dies del mes d'octubre, 3 diners.

Item, rebé lo dit honrat Justícia d'en Bertomeu Bernabeu per ço com lo seu bestiar era entrat en lo plantat de Sereya, d'en Johan Bernabeu, divendres ha XIIII dies del mes d'octubre, 1 diner.

Item, rebé lo dit honrat Justícia del quarnicer per tal com avia més lo seu bestiar en lo real d'en Garcia Pereç, del cap del raval, diluns ha XXVII dies del mes de denbre, 4 diners.

Item, rebé lo dit honrat Justícia de hun quart que fon acussat a'n Bertomeu Rovira, lo qual era obligat en quantitat de $X$ sous a'n Jaume Garcia, en lo libre de la sua quort e del seu ayn, 4 diners.

Item, rebé lo dit honrat Justícia d'en Jaume de Moya, de quart que li fon acussat per en Ramon Margalit, lo qual era obligat en quantitat de XVI sous en lo libre del seu dit any, 6 diners.

Item, rebé lo dit honrat Justícia de quart que fou acussat a'n Ramon Margalit, lo qual era obligat a'n Arnau Sera, prevere, en quantitat de XVI sous, 6 diners.

Suma plàgina, 2 sous 3 diners.

[f.293vํㅡ Item, rebé lo dit honrat Justícia d'en Bernat d'Arques per ço com entraven les sues quabres en lo bovalar de Bugaya, per dimarts ha VII dies del mes de denbre, 4 diners.

Item, rebé lo dit honrat Justícia d'en Bernat d'Arques per ço com lo seu bestiar era entrat en lo bovalar de Bugaya, dimarts ha VII dies del mes de denbre, 3 diners.

Item, rebé lo dit honrat Justícia d'en Bernat Bernabeu e d'en Pere Deçpí per ço com meteren un bestiar en lo bovalar de Bugaya, diluns ha VII dies del mes de noembre, 5 diners. 
Item, rebé lo dit honrat Justícia d'en Bernat d'Arques per ço com més lo seu bestiar en lo bovalar de Bugaya, a digous, ha $X$ dies del mes de noembre, 3 diners.

Item, rebé lo dit honrat Justícia d'en Jaume Cremades perquè més lo seu bestiar en lo bovalar de Bugaya, diluns ha XX dies del mes de noenbre, 2 diners.

Item, rebé lo dit honrat Justícia d'en Bernat Bernabeu perquè entraren les sues bèsties en la erba de la daxca de Matheu Garcia, del Cafarixet, divendres ha XXII dies del mes de denbre, 1 diner.

Suma plàgina, 1 sou 4 diners.

[f.294ro $]$ Digous, ha quatre dies del mes de giner del ayn de la Nativitat de nostre Senyor d'en Jhesu Christ M CCCC e XIIII.

L'onrat en Ramon Quasteló, Justícia en l'ayn pus prop pasat, rete comte de les quoses damunt dites al molt onrat en Bernat Bernabeu, tinent loch de batle per lo molt honorable micer Johan Merquader, doctor en leys e Batle General del Regne de València, presents los honrats en Bertomeu Bernabeu, en Garcia Pereç, en Bernat d'Arques, en Johan Garcia, Jurats, e d'atres bons hòmens, e muntaren les dites rebudes XXIIII sous VII diners.

Testes en Sanxo Verdú, en Guerau Bernabeu, veïns de la vila de Sexona.

Item aquest dia matex lo dit honrat en Ramon Quasteló féu sagrament e jurà que pus ni més non avia prés si no tant com en lo dit comte hera atrobat.

INDEX ONOMASTIC DELS VEINS DE XIXONA EN 1413.

AÇNAR, Domingo.

ALMENARA, Bernat d'.

ALMENARA, na Gontança d'.

ARACIL, Francesc d'.

ARQUÉS, Antoni d'.

ARQUÉS, Bernat d', jurat de l'any 1413.

ARQUÉS, Francesc d'.

ARQUÉS, Joan, major, Justícia de l'any 1410.

ARQUÉS, Joan, menor, Justícia de l'any 1412.

ARQUÉS, Miquel d'.

BENEYTO, Jaume.

BERNABEU, Bernat, Justícia de l'any 1411.

BERNABEU, Bernat, menor.

BERNABEU, Bernat, de l'almàssera.

BERNABEU, Bernat, lo batlle.

BERNABEU, Bertomeu, mostassà de l'any $1411 \mathrm{i}$ jurat de l'any 1413.

BERNABEU, Guerau.

BERNABEU, Joan. 
BERNABEU, Pere, mostassà el 1408.

BERNABEU, Pere, menor.

BLASCO, Jaume, ferrer.

BLANES, Domingo de.

BROTONS, Bernat.

BROTONS, Pere, mostassà de l'any 1409 .

Capellà del poble.

CARBONELL, Domingo.

CARBONELL, Francesc.

CARBONELL, Joan.

Carnisser del poble.

CASTELLÓ, Ramon, Justícia dels anys 1409 i 1413.

COLOMINA, Berenguer.

COLOMINA, Joan.

CREMADES, Jaume.

ENEGUES, Guillem.

ESPI Arnau d'.

ESPÍ, Pere d'.

ESPINÓS, Pere, d'Alcoi.

FORTUNYO, Ginés.

GARCIA, Guillem.

GARCIA, Ivanyes, major, mostassà de l'any 1410.

GARCIA, Ivanyes, menor.

GARCIA, Jaume.

GARCIA, Joan, jurat de l'any 1413.

GARCIA, Mateu.

GARCIA, Mateu, fill de Jaume Garcia.

GARCIA, Miquel.

GARRIGÓS, Domingo.

GUAYTES, Domingo, d'Alcoi.

GUILLEM, Joan, Justícia de l'any 1408.

GUILLEM, Joan, menor, son fill.

LOPIÇ, Domingo.

LOPIÇ, Eximeno, mostassà de l'any 1413.

MARCO, Bernabeu.

MARCO, Mateu.

MARGALIT, Ramon.

MIRA, Joan de.

MORANT, Joan.

MORANT, Pascual.

MOYA, Jaume de.

PEREÇ, Garcia, jurat de l'any 1413.

PEREÇ, Nadal.

PERPENYà, Mateu.

PURAG, d'Alcoi. 
ROVIRA, Bertomeu.

SENGAREN, Guillem.

SENTPERE, Sanxo.

SERRA, Arnau.

SERRA, Arnau, prevere.

SERVENTA, na.

SOLER, Jaume.

TORREGROSA, Bernat.

VENRELL, Guillem, notari de Xixona.

VERDÚ, Joan, mostassà de l'any 1412.

VERDÚ, Pere.

VERDÚ, Sanxo.

VILAR, Sanxo.

NOM DE LES PARTIDES IDENTIFICADES DEL TERME DE XIXONA EN 1413.

ALETGUA, horta d'.

ALMARG.

ALMORAYAG.

BUGAYA.

CANAL, la.

CANALETA, barranc de la.

CARRASQUES.

CATELLES.

COSTA.

FABRA.

JUNQUARET.

LOBERA.

MONTAGUT.

NUXES.

PENYES ROGES-PENYA ROJA.

PINETA, bovalar de.

RAFAL.

RAVAL.

SERRAT, riu de.

SERREYA-SERREIA.

SOT.

XENDIQUER. 